\title{
Synthesis of hierarchical CuS flower-like submicrospheres via an ionic liquid-assisted route
}

\author{
LIHUA WANG ${ }^{\dagger}$, CHAO $\mathrm{XU}^{\dagger}$, DINGBING ZOU ${ }^{\dagger}$, HAO LUO ${ }^{\dagger}$ and TAOKAI YING* \\ Institute of Physical Chemistry, Zhejiang Normal University, Jinhua 321004, PR China \\ ${ }^{\dagger}$ College of Chemistry and Life Sciences, Zhejiang Normal University, Jinhua 321004, PR China
}

MS received 16 May 2008; revised 27 June 2008

\begin{abstract}
A facile, ionic liquid-assisted route was developed to synthesize hierarchical CuS flower-like submicrospheres at $80^{\circ} \mathrm{C}$ for $24 \mathrm{~h}$. The method was based on a reaction between $\mathrm{CuCl}_{2}$ and thioacetamide (TAA) in aqueous solution with using ionic liquid 1-n-butyl-3-methylimidazolium chloride ([BMIM]CI) as an assisted agent. The chemical composition, morphology and size of CUS product were characterized by XRD, SEM and TEM. The result shows that the as-prepared CuS consists of flowery spheres with a diameter of $0.6 \sim 1.0 \mu \mathrm{m}$, and these submicrospheres are, in fact, built by numerous nanoflakes with a thickness of $10 \sim 20 \mathrm{~nm}$. The optical property of CuS product was examined by UV-Vis. In general, we suggested an ecologically and environmentally friendly route for the syntheses of hierarchical metal chalcogenides structures in this paper.
\end{abstract}

Keywords. Copper sulfide; ionic liquids; nanomaterials; semiconductors.

\section{Introduction}

There has been considerable effort in synthesizing inorganic materials with hierarchical nano-/microstructures, which are desirable for many applications in optics, electronics, biology, medicine, and energy/chemical conversions. To date, a wide variety of inorganic materials, including metal (Teng and Yang 2005; Shen et al 2007), metal oxide (Liu and Zeng 2004), sulfide (Xie and Zhao 2002), hydrate (Zhang et al 2005) and other minerals (Murray et al 1995; Yu and Chen 2006), have been successfully prepared with hierarchical shapes.

Semiconductor materials have recently attracted much attention because of their novel properties and potential applications in manufacturing electronic and optoelectric devices (Duan et al 2001; Cui and Lieber 2001; Huang et al 2001). Besides being an excellent semiconductor, copper sulfide $(\mathrm{CuS})$ also exhibits its commercial importance as pigment, catalyzer, solar energy conversion, and coloured indicator of nigrosine and so forth. On the basis of the versatile applications of the $\mathrm{CuS}$ material, a large effort has been focused on the synthesis and characteristics of the $\mathrm{CuS}$ nano-/microstructures. The reported methods for formation of $\mathrm{CuS}$ material mainly included sonochemical methods (Wang et al 2002), microwave-assisted methods (Liao et al 2003), electrosynthesis (Cordova et al 2002), hydrothermal methods (Tang et al 2004), solid-state reactions (Parkin 1996), and chemical vapour deposition (CVD)

\footnotetext{
*Author for correspondence (sky50@zjnu.cn)
}

(Nomura et al 1996). However, a simple, mild and environmentally friendly preparation route for intriguing hierarchical $\mathrm{CuS}$ architectures still remains a highly sophisticated challenge.

Room temperature ionic liquids (RTILs) can be defined as electrolytes composed entirely of ions at ambient temperature, and have applications in organic synthesis (Bar et al 2001; Lee et al 2001; Potdar et al 2001), electrochemistry (Lin and Sun 1999; Tsuda et al 2001) and separation (Visser et al 2000; Anthony et al 2001; Dzyuba and Bartsch 2003). Their applications in inorganic field, however, are still in infancy. From theoretical points of view, ionic liquids can act as co-solvents for reactants and morphological templates for products at the same time, and facilitate the syntheses of inorganic materials with novel or improved properties.

In this paper, we reported the hydrothermal synthesis of hierarchical $\mathrm{CuS}$ flower-like submicrospheres at $80^{\circ} \mathrm{C}$ for $24 \mathrm{~h}$ in the presence of [BMIM]Cl, and demonstrated that this ionic liquid played an important role in the formation of $\mathrm{CuS}$ with the hierarchical flowerlike structure.

\section{Experimental}

\subsection{Synthesis of hierarchical CuS flower-like submicrospheres}

Ionic liquid 1-n-butyl-3-methylimidazolium chloride ([BMIM]Cl) was synthesized according to the literature (Huddleston et al 1998). All the other chemicals were purchased from commercial sources and used without 
further purification. In a typical synthetic procedure for $\mathrm{CuS}, 2$ equivalents of $1-n$-butyl-3-methylimidazolium chloride $(4.8 \mathrm{mmol})$ and 1 equivalent of $\mathrm{CuCl}_{2} \cdot 2 \mathrm{H}_{2} \mathrm{O}$ $(2.4 \mathrm{mmol})$ were heated to $140^{\circ} \mathrm{C}$ for $10 \mathrm{~min}$ to get dark red, sticky liquid after cooling. The sticky liquid was dissolved in $40 \mathrm{~mL}$ of distilled water to form a homogeneous blue solution in a glass jar under constant stirring. Then $0.18 \mathrm{~g}$ of TAA was dissolved in $40 \mathrm{~mL}$ of distilled water, and subsequently added into the jar with $\mathrm{CuCl}_{2}$ solution gradually without stirring or vibration. Then the jar was covered and maintained at $80^{\circ} \mathrm{C}$ for $24 \mathrm{~h}$. The resulting black solid product was filtered, washed with distilled water and absolute ethanol in sequence, and then dried in a vacuum at $60^{\circ} \mathrm{C}$ for $6 \mathrm{~h}$.

\subsection{Characterization of as-prepared CuS product}

X-ray diffraction (XRD) patterns were collected on a Philips-PW3040/60 X-ray diffractometer with $\mathrm{K} \alpha$ radiation $(\lambda=0 \cdot 15418 \mathrm{~nm})$. Scanning electron microscopy (SEM) measurements were carried out with a HITACHI S-4800 field-emission microscope operated at an accelerating voltage of $5 \mathrm{kV}$. Transmission electron microscopy (TEM) was performed using a JEOL-2010 instrument at an accelerating voltage of $200 \mathrm{kV}$. An UV-2501 PC ultraviolet-visible light (UV-Vis) spectrophotometer was used to carry out the optical measurements of sample dispersed in ethanol in the wavelength range of $200 \sim 800 \mathrm{~nm}$.

\section{Results and discussion}

The crystallinity and phase structure of the as-prepared $\mathrm{CuS}$ were examined by powder XRD. Figure 1 shows a typical XRD pattern of the product. All the diffraction peaks in the pattern can be indexed to pure hexagonalphase $\mathrm{CuS}$, which are consistent with the standard card (JCPDS Card 65-3556). No XRD peaks arising from impurities of $\mathrm{CuO}, \mathrm{CuCl}_{2}$ and $\mathrm{Cu}_{2} \mathrm{~S}$ can be detected, which indicates that pure $\mathrm{CuS}$ can be easily obtained under the current synthetic conditions. In addition, the sharp diffraction peaks reveal good crystallinity of the $\mathrm{CuS}$ sample.

The morphology of the as-synthesized CuS was investigated by SEM and TEM microscopies. Figure 2a shows the SEM image at a low magnification, and reveals that the product is composed of a large quantity of nearly monodispersed submicrospheres with a diameter of 0.6 $1.0 \mu \mathrm{m}$. Figure $2 \mathrm{~b}$ is the SEM image at a high magnification. It shows these $\mathrm{CuS}$ spheres have a flower-like hierarchical morphology and a nanoflakes-built superstructure. Figure 2c displays a representative TEM image of a single $\mathrm{CuS}$ sub-microsphere, where we can find the hierarchical sphere built by numerous nanoflakes with a thickness of 10 20 nm.

Figure 3 shows the UV-Vis absorption spectra of the as-prepared $\mathrm{CuS}$ flower-like submicrospheres dispersed in ethanol. It is interesting to note that two strong absorption peaks located at 255 and $503 \mathrm{~nm}$ occur in this spectra, which is obviously different from that of $\mathrm{CuS}$ nanoflakes (Xu et al 2006; Zhang and Zhang 2008), nanowires (Wu et al 2008), and hollow spheres (Yu et al 2007). In addition, the sample shows an increased absorption band in near-IR region, which is characteristic of covellite $\mathrm{CuS}$ (Haram et al 1996; Dixit et al 1998). The unusual phenomena in the UV-Vis absorption spectra may have potential applications in the optical field.

The influence of synthetic parameters, such as reaction temperature and [BMIM]Cl, on the morphologies of the products are investigated. Experiments at different hydrothermal temperatures such as $60,70,90$, and $100^{\circ} \mathrm{C}$ were performed while keeping other reaction parameters constant, and the corresponding SEM images of products are shown in figures $4 \mathrm{a}-\mathrm{d}$. When the sample was prepared at $60^{\circ} \mathrm{C}$, the ill-defined flower-like $\mathrm{CuS}$ aggregations assembled by some plates was obtained (figure 4a). This structure is loose with an irregular shape, and seems to be underdeveloped. Figure $4 \mathrm{~b}$ illustrates a typical SEM image of the $\mathrm{CuS}$ quasi-spheres attained at $70^{\circ} \mathrm{C}$. No individual nanoplates can be found, indicating the acquirement of hierarchical architectures. However, when the temperature was raised to 90 or $100^{\circ} \mathrm{C}$, a majority of regular hierarchical flower-like structures were destroyed as seen in figures $4 \mathrm{c}-\mathrm{d}$, and many smaller irregular spheres formed. In the formation of hierarchical $\mathrm{CuS}$ flower-like submicrospheres, the reaction temperature played an important role. SEM observations suggest that the hierarchical $\mathrm{CuS}$ flower-like structures could only be perfectly constructed in the temperature range of $70 \sim 80^{\circ} \mathrm{C}$.

A similar experiment was also done in the absence of any ionic liquid at $80^{\circ} \mathrm{C}$ for $24 \mathrm{~h}$. As shown in figure 5, the final product has an ill-defined tubular structure com-

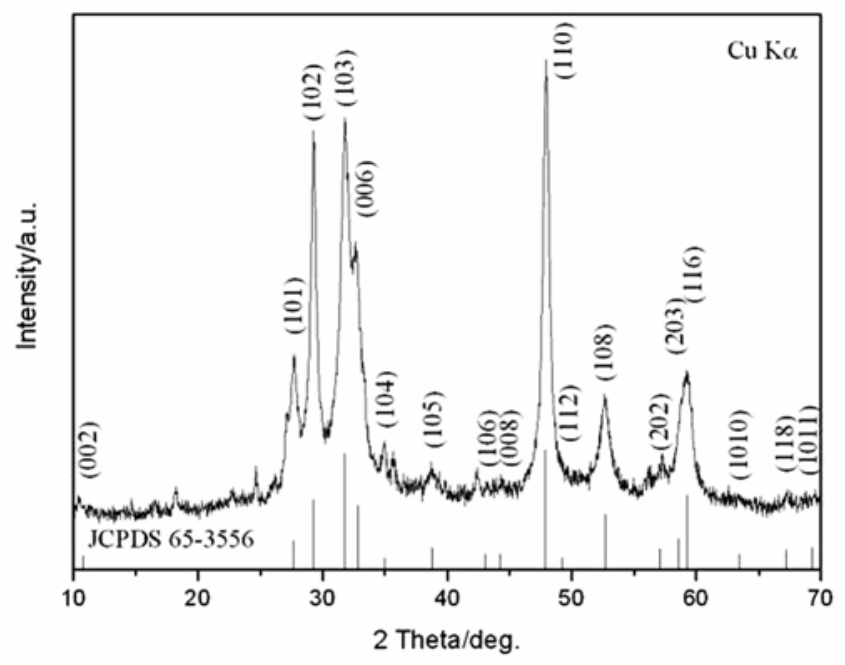

Figure 1. Powder X-ray diffraction pattern of hierarchical CuS flower-like submicrospheres. 

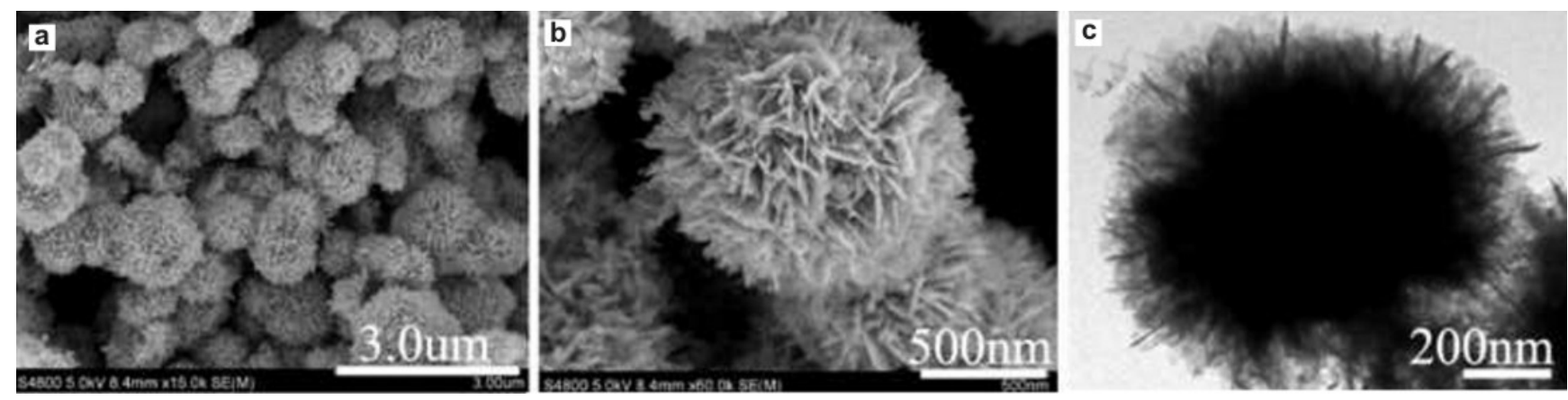

Figure 2. SEM (a, b) and TEM (c) images of hierarchical CuS flower-like submicrospheres.

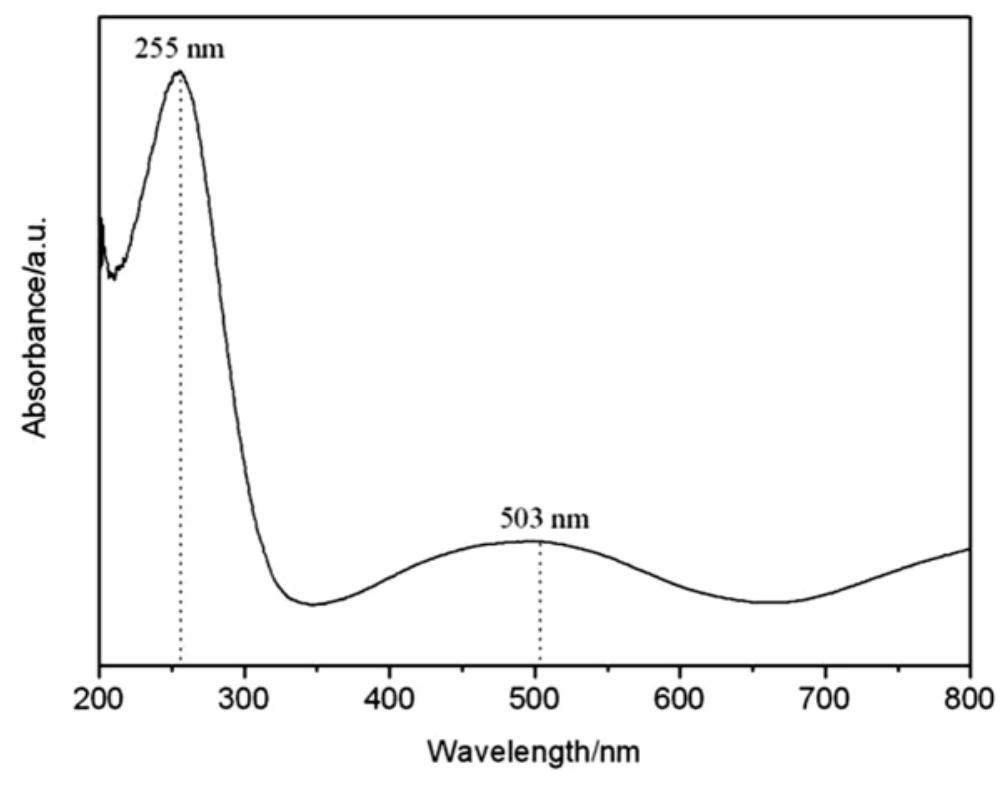

Figure 3. UV-Vis absorption spectra of hierarchical CuS flower-like submicrospheres.

posed of aggregated microspheres, where the total length of single tube is more than $10 \mu \mathrm{m}$ and the extra diameter of the tube is about $4 \sim 5 \mu \mathrm{m}$. This morphology is obviously different from that of hierarchical flower-like $\mathrm{CuS}$ obtained in the presence of ionic liquid [BMIM]Cl. Thus, ionic liquid in our experiments also plays a vital role in the formation of the as-obtained hierarchical flower-like structures. Firstly, the strong combination between $\mathrm{Cl}^{-}$ and $\mathrm{CuCl}_{2}$ results in the formation of an ionic liquid salt comprising of $\mathrm{CuCl}_{4}^{2-}$ anions at $140^{\circ} \mathrm{C}$ for $10 \mathrm{~min}$ (Hardacre et al 2001; Neve et al 2001; Lee et al 2004). Then $\mathrm{CuCl}_{4}^{2-}$ ions hydrolyze to release $\mathrm{Cu}^{2+}$ very slowly after being mixed with water due to the hinderance of the bislamellar cations, so here the cations are good buffer, which can keep a suitable hydrolysis rate of $\mathrm{CuCl}_{4}^{2-}$ in this reaction system. Finally, suitable hydrolysis rate can control the formation and decomposition of precursor particles originating from the initial reaction between
$\mathrm{CuCl}_{2}$ and TAA, the nucleation speed of $\mathrm{CuS}$ nuclei, the growth rate of $\mathrm{CuS}$ nanoflakes, and their assembly into submicrospheres. In addition, the reformed ionic liquid [BMIM] Cl can act as the surfactant or morphological template, which may be responsible for such hierarchical structures as discussed previously in our report (Xu et al 2008). The probable reaction processes for the ionic liquid-assisted formation of $\mathrm{CuS}$ in aqueous solution can be summarized as follows:

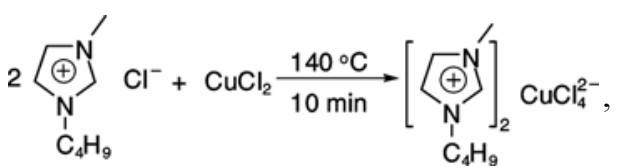

$$
\begin{aligned}
& \mathrm{CuCl}_{4}^{2-}+4 \mathrm{H}_{2} \mathrm{O} \rightarrow \mathrm{Cu}\left(\mathrm{H}_{2} \mathrm{O}\right)_{4}^{2+}+4 \mathrm{Cl}^{-1}, \\
& \mathrm{Cu}^{2+}+\mathrm{TAA}+\mathrm{H}_{2} \mathrm{O}+\mathrm{O}_{2} \rightarrow \\
& \mathrm{CuS}+\mathrm{CH}_{3} \mathrm{COO}^{-}+\mathrm{NH}_{4}^{+}+\mathrm{H}^{+}+\mathrm{Cl}^{-}+\mathrm{SO}_{4}^{2-} \text {. }
\end{aligned}
$$



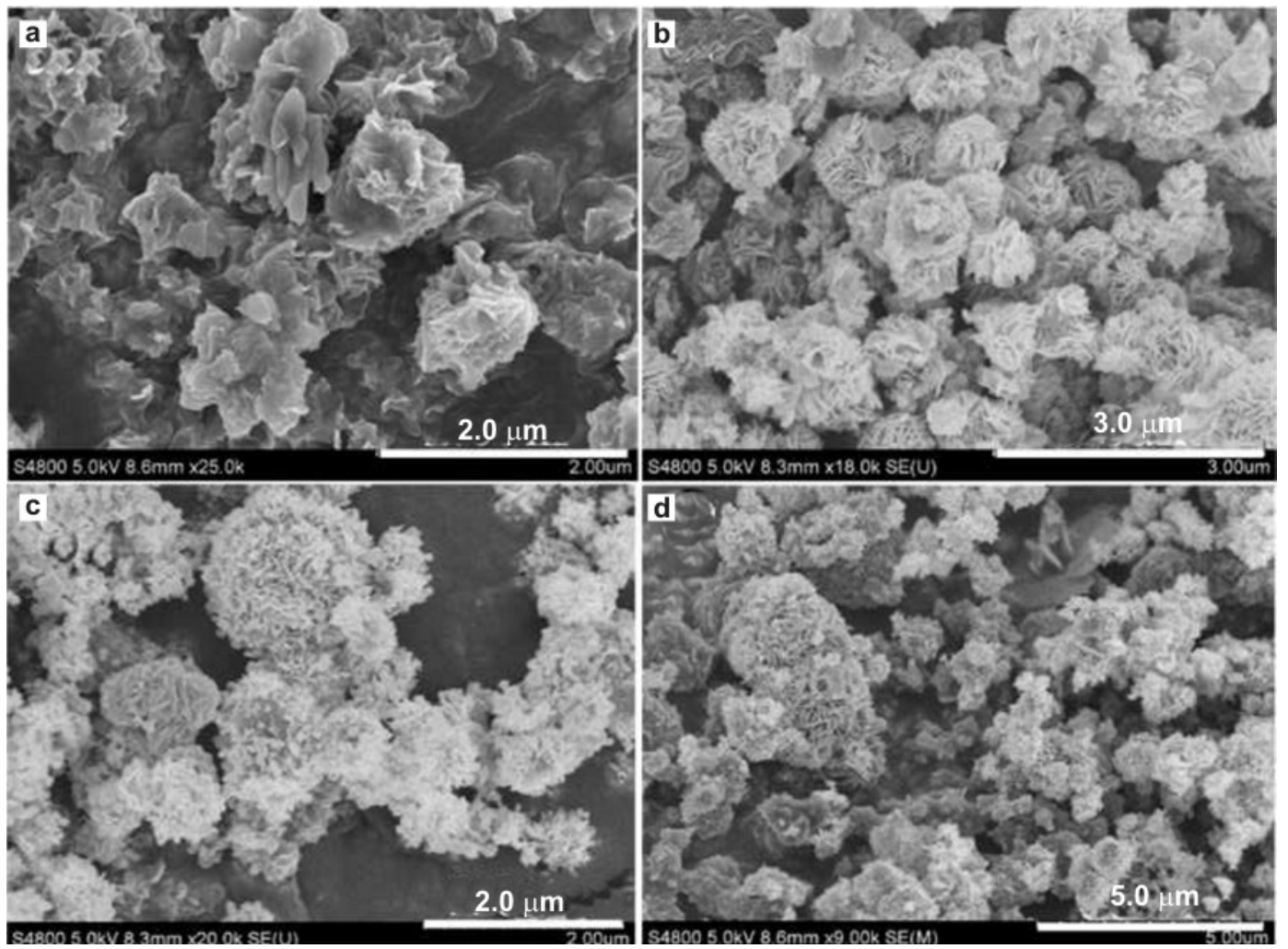

Figure 4. SEM images of CuS samples synthesized at different hydrothermal temperatures: a. 60, b. 70, c. 90 and d. $100^{\circ} \mathrm{C}$.

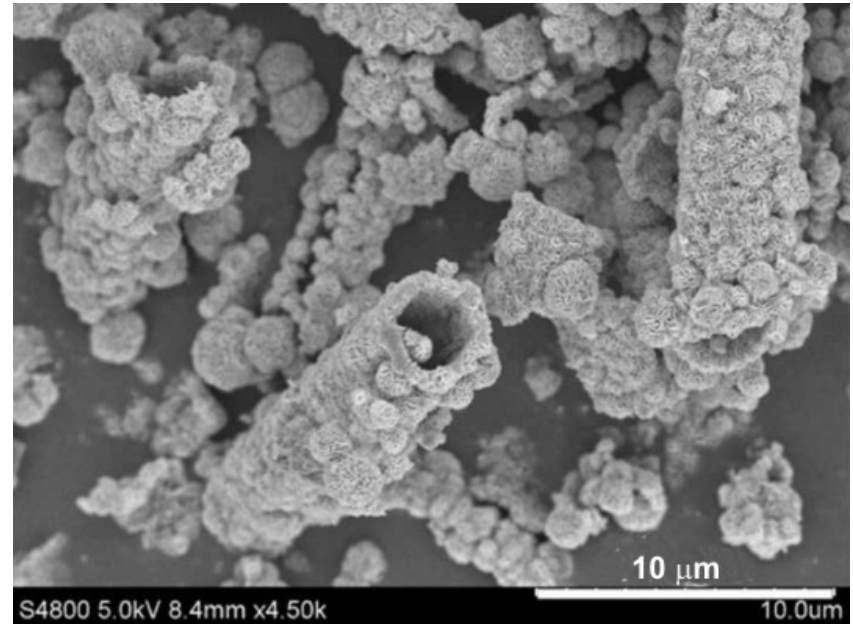

Figure 5. SEM image of CuS sample prepared in the absence of ionic liquid.

\section{Conclusions}

In summary, a mild method for the synthesis of the hierarchical CuS flower-like submicrospheres has been described. The intriguing hierarchical $\mathrm{CuS}$ structures were prepared using an ionic liquid [BMIM]Cl as an assisted agent at $80^{\circ} \mathrm{C}$ for $24 \mathrm{~h}$, and characterized by XRD, SEM, TEM and UV-Vis. In addition, we found both the reac- tion temperature and ionic liquid played important roles on the morphology of $\mathrm{CuS}$ product. This simple, ecological and environment friendly preparation route is expected to extend to prepare other hierarchical metal chalcogenides structures.

\section{References}

Anthony J L, Maginn E J and Brennecke J F 2001 J. Phys. Chem. B105 10942

Bar G, Parsons A F and Thomas C B 2001 Chem. Commun. 1350

Cordova R et al 2002 Langmuir 188647

Cui Y and Lieber C M 2001 Science 291851

Dixit S G, Mahadeshwar A R and Haram S L 1998 Colloids Surf. A133 69

Duan X F, Huang Y, Cui Y, Wang J and Liber C M $2001 \mathrm{Na-}$ ture 40966

Dzyuba S V and Bartsch R A 2003 Angew. Chem. Int. Ed. 42 148

Haram S K, Mahadeshwar A R and Dixit S G 1996 J. Phys. Chem. 1005868

Hardacre C, Holbrey J D, McCormac P B, McMath S E J, Nieuwenhuyzen M and Seddon K R 2001 J. Mater. Chem. 11 346

Huang H M et al 2001 Science 2921897

Huddleston J G, Willauer H D, Swatloski R P, Visser A E and Rogers R D 1998 Chem. Commun. 1765 
Lee C K, Han P H and Lin I J B 2004 Chem. Mater. 16530

Lee S, Park J H, Kang J and Lee J K 2001 Chem. Commun. 1698

Liao X H, Chen N Y, Xu S, Yang S B and Zhu J J 2003 J. Cryst. Growth 252593

Lin Y F and Sun I W 1999 Electronchim. Acta 442771

Liu B and Zeng H C 2004 J. Am. Chem. Soc. 12616744

Murray C B, Kagan C R and Bawendi M G 1995 Science 2701335

Neve F, Francescangeli O, Crispini A and Charmant J 2001 Chem. Mater. 132032

Nomura R, Miyawaki K, Toyosaki T and Matsuda H 1996 Chem. Vap. Depos. 2174

Parkin I P 1996 Chem. Soc. Rev. 25199

Potdar M K, Mohile S S and Salunkhe M M 2001 Tetrahedron Lett. 429285

Shen G Z, Bando Y and Golberg D 2007 Cryst. Growth Des. 735

Tang K B, Chen D, Liu Y F, Shen G Z, Zheng H G and Qian Y T 2004 J. Cryst. Growth 263232
Teng X W and Yang H 2005 Nano. Lett. 5885

Tsuda T, Nohira T and Ito Y 2001 Electrochim. Acta 461891

Visser A E, Swatloski R P, Reichert W M, Griffin S T and Rogers R D 2000 Ind. Eng. Chem. Res. 393596

Wang H, Zhang H R, Xiao X N, Xu S and Zhu J J 2002 Mater. Lett. 55253

Wu C, Shi J B, Chen C J, Chen Y C, Lin Y T, Wu P F and Wei S Y 2008 Mater. Lett. 621074

Xie S H and Zhao D Y 2002 Adv. Mater. 141537

Xu C, Wang L, Zou D B and Ying T K 2008 Mater. Lett. 62 3181

Xu H L, Wang W Z and Zhu W 2006 Mater. Lett. 602203

Yu S H and Chen S F 2006 Curr. Nanosci. 281

Yu X L, Cao C B, Zhu H S, Li Q S, Liu C L and Gong Q H 2007 Adv. Funct. Mater. 171397

Zhang J and Zhang Z K 2008 Mater. Lett. 622279

Zhang Z, Sun H, Shao X, Li D, Yu H and Han M $2005 A d v$. Mater. 1742 